
Raylla Virgínia S. Ramalho Souza

Fernanda Pires do Nascimento Arena

Juliana Sayuri Kimura

Marcia Turola Wanderley

Michele Baffi Diniz

Tatiane Fernandes Novaes

\section{TRAUMATISMO DENTÁRIO EM CRIANÇAS}

São Paulo 
Traumatismo dentário em crianças. / Raylla Virgínia S. Ramalho Souza, Fernanda Pires do Nascimento Arena, Juliana Sayuri Kimura, Marcia Turola Wanderley, Michele Baffi Diniz, Tatiane Fernandes Novaes. São Paulo: Cruzeiro do Sul Educacional, 2020.

30 f. il.

Inclui bibliografia

ISBN: 978-65-88103-00-5 (e-book)

1. Odontopediatria. I. Souza, Raylla Virgínia S. Ramalho. II. Arena, Fernanda Pires do Nascimento. III. Kimura, Juliana Sayuri. IV. Wanderley, Marcia Turola. V. Diniz, Michele Baffi. VI. Novaes, Tatiane Fernandes. VII. Título. 


\section{E-BOOK}

\section{INTERATIVO}

Clique nos links para abrir is a página da referência

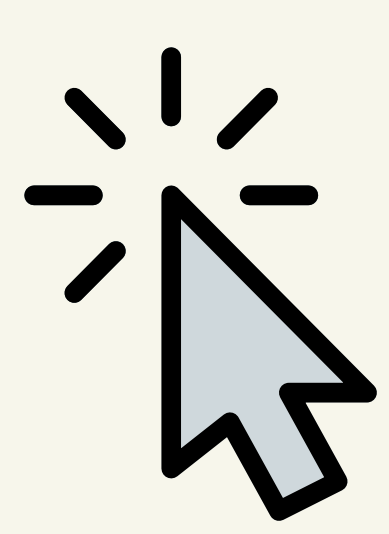

citada. 


\section{OB JETIVO}

A ocorrência do traumatismo dentário sempre gera muitas dúvidas.

Devido à atual pandemia de Covid-19, os traumatismos dentários têm acontecido em casa, onde as famílias cumprem a recomendação de isolamento social. No entanto, em períodos normais, os traumas também podem acontecer nas escolas.

Além do medo e insegurança inerentes a esses momentos, muitos não sabem como agir quando a criança cai e bate os dentes de leite.

Assim, o objetivo deste material interativo é informar sobre o traumatismo em dentes de leite, além de orientar pais e professores de educação infantil como proceder frente à sua ocorrência. 


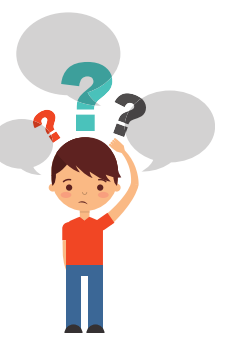

\section{VOCÊ \\ CONHECE \\ O \\ DENTE DECIDUO?}

O dente decíduo também é conhecido como "dente de leite".

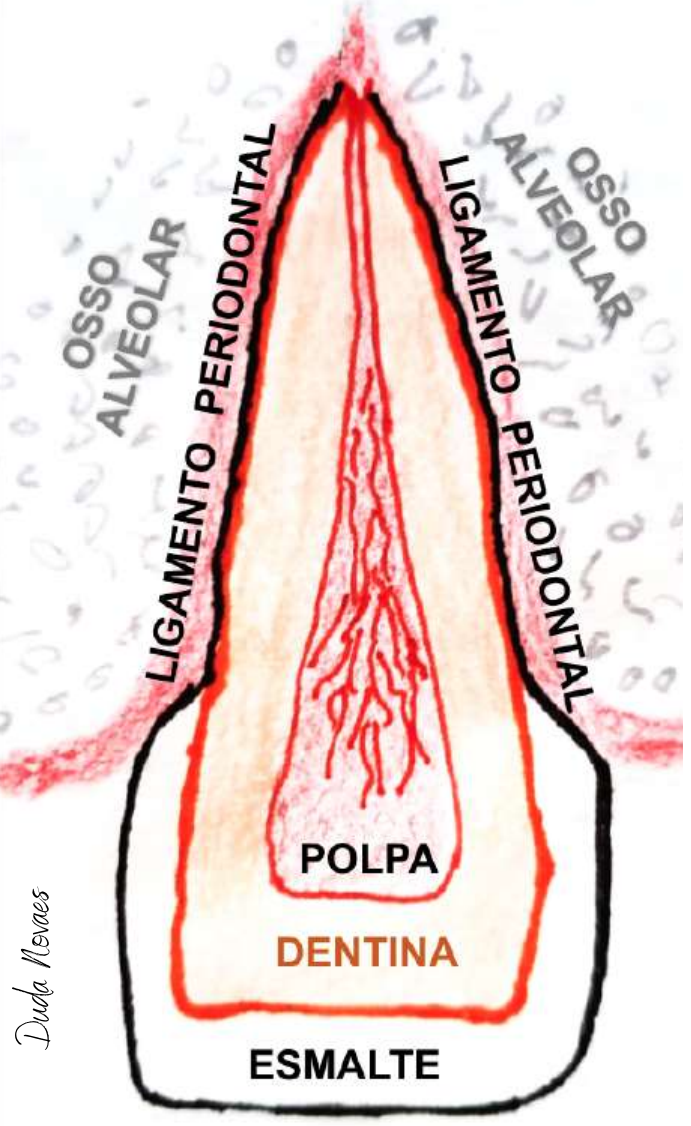

O osso alveolar e o ligamento periodontal são tecidos de suporte, que mantém o dente na boca.

O esmalte e a dentina formam a coroa dentária, que é a parte mais visível do dente.

A polpa é o "coração" do dente. Se ela ficar doente, você pode ter dor de dente. 


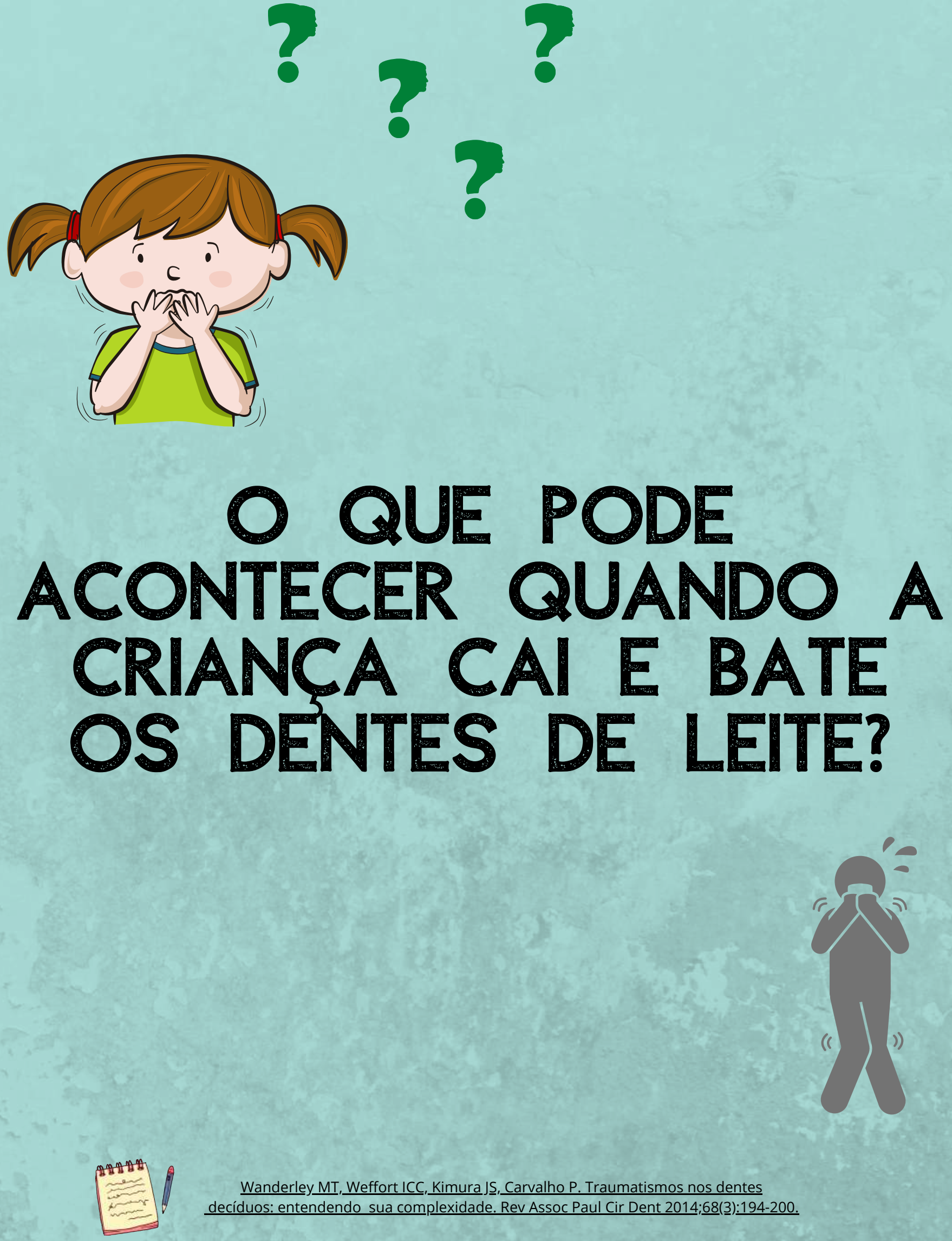




\section{O DENTE PODE FRATURAR ("QUEBRAR")}

\section{APRESENTAR MOBILIDADE ("FICAR MOLE")}

\section{SE DESLOCAR E MUDAR DE POSIÇÃO}

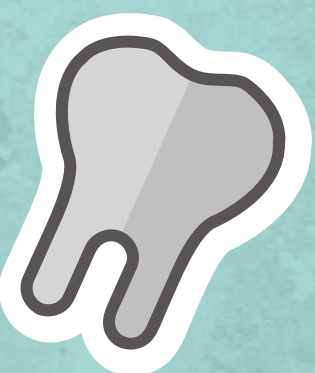

\section{OU ATÉ MESMO PODE SAIR COMPLETAMENTE DA BOCA.}




\section{FRATURA DE}

\section{ESMALTE}

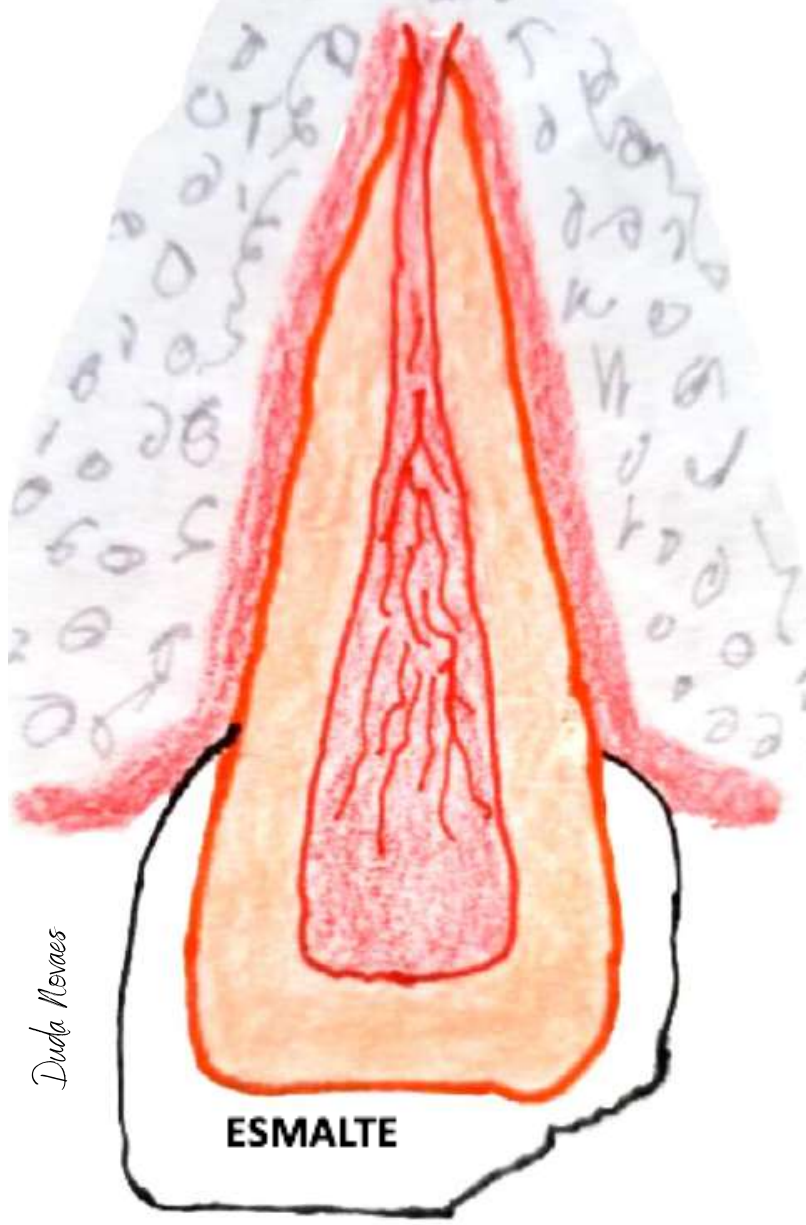

\section{Apenas 0 esmalte, a parte mais}

externa e visivel do dente, é quebrada.

NESSES CASOS, GERALMENTE A CRIANÇA NÃO TEM DOR.

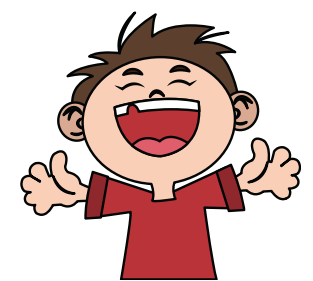




\section{FRATURA DE ESMALTE}

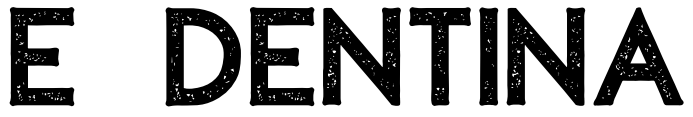

\section{A fratura}

dentária é um

pouco maior,

envolvendo 0

esmalte e a

dentina.

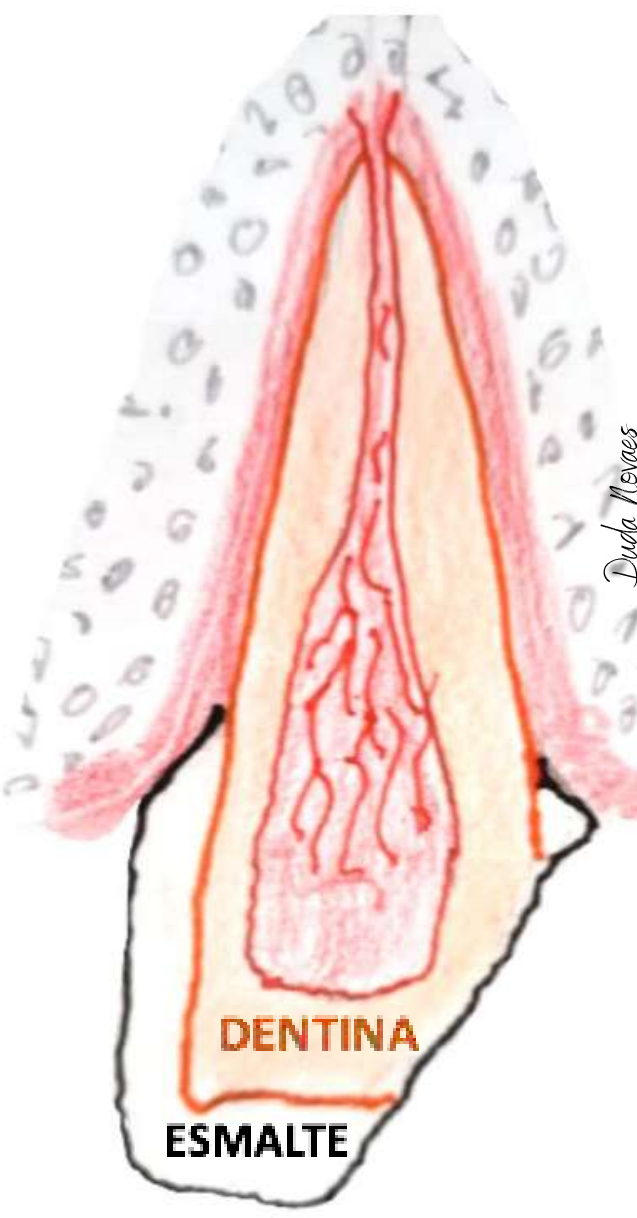

Wanderley MT, Weffort ICC, Kimura JS, Carvalho P. Traumatismos nos dentes

decíduos: entendendo sua complexidade. Rev Assoc Paul Cir Dent 2014; 6 (3)(3):194-200. 


\section{FRATURA DE ESMALTE}

E DENTINA COM EXPOSIÇÃO PULPAR

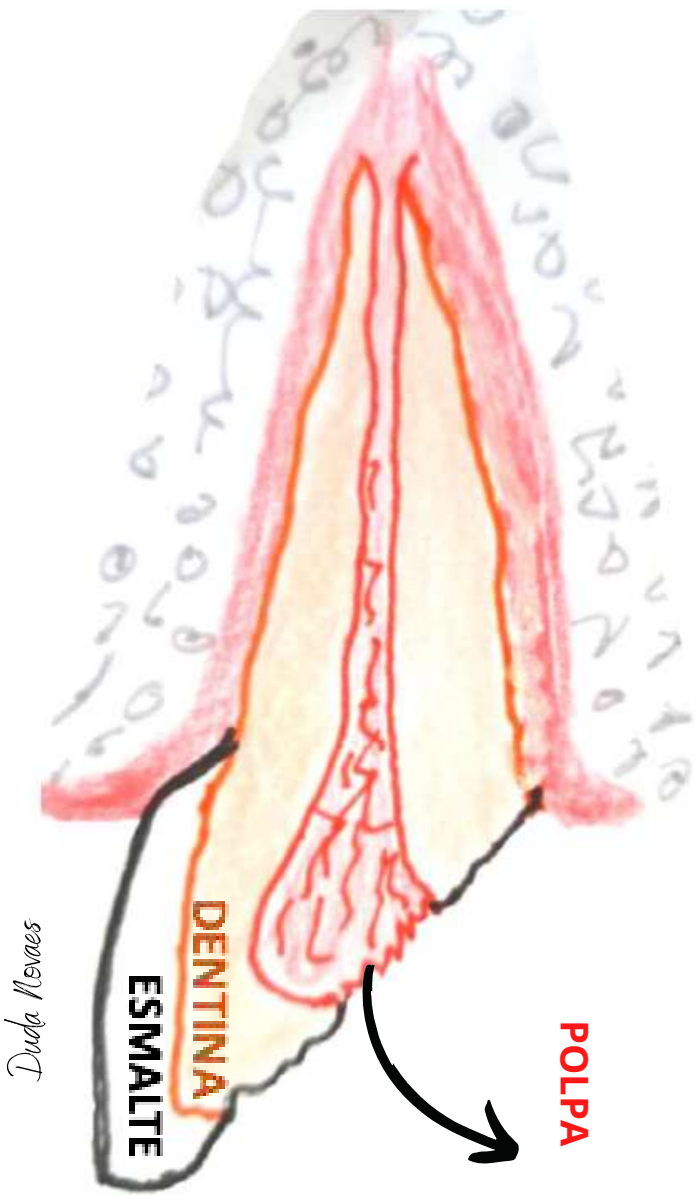

Nesses casos,

a fratura

dentária

envolve 0

esmalte, a

dentina

e também a

polpa.

A CRIANÇA PODE SENTIR DOR E DEVE SER IMEDIATAMENTE LEVADA A UM DENTISTA!

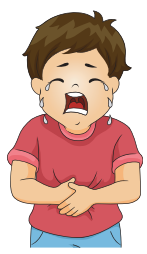



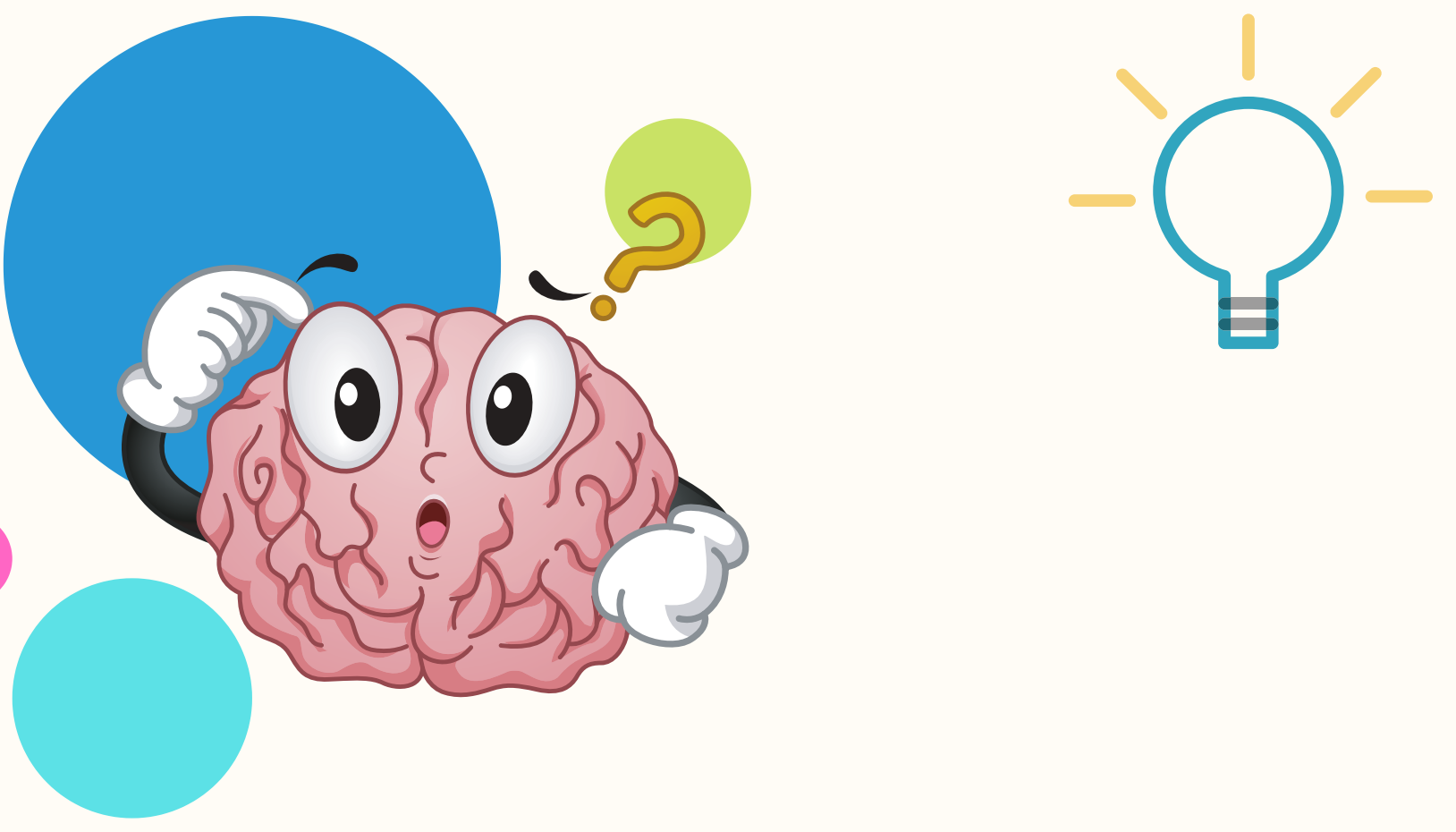

O QUE FAZER EM

CASOS DE

FRATURAS

DENTÁRIAS NOS

DENTES DE LEITE? 
SE POSSIVEL, ENCONTRE O FRAGMENTO DO DENTE. ELE PODE SER REPOSICIONADO E "COLADO" DE VOLTA AO SEU LUGAR.

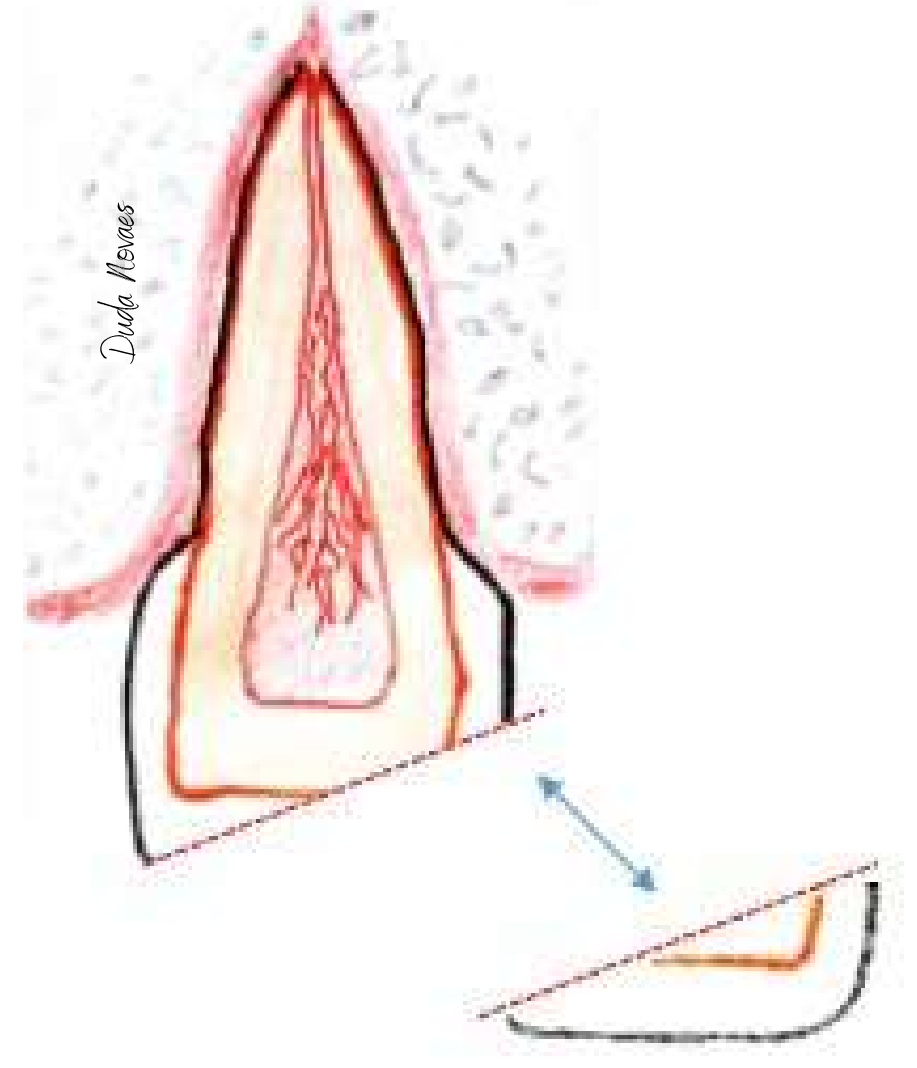







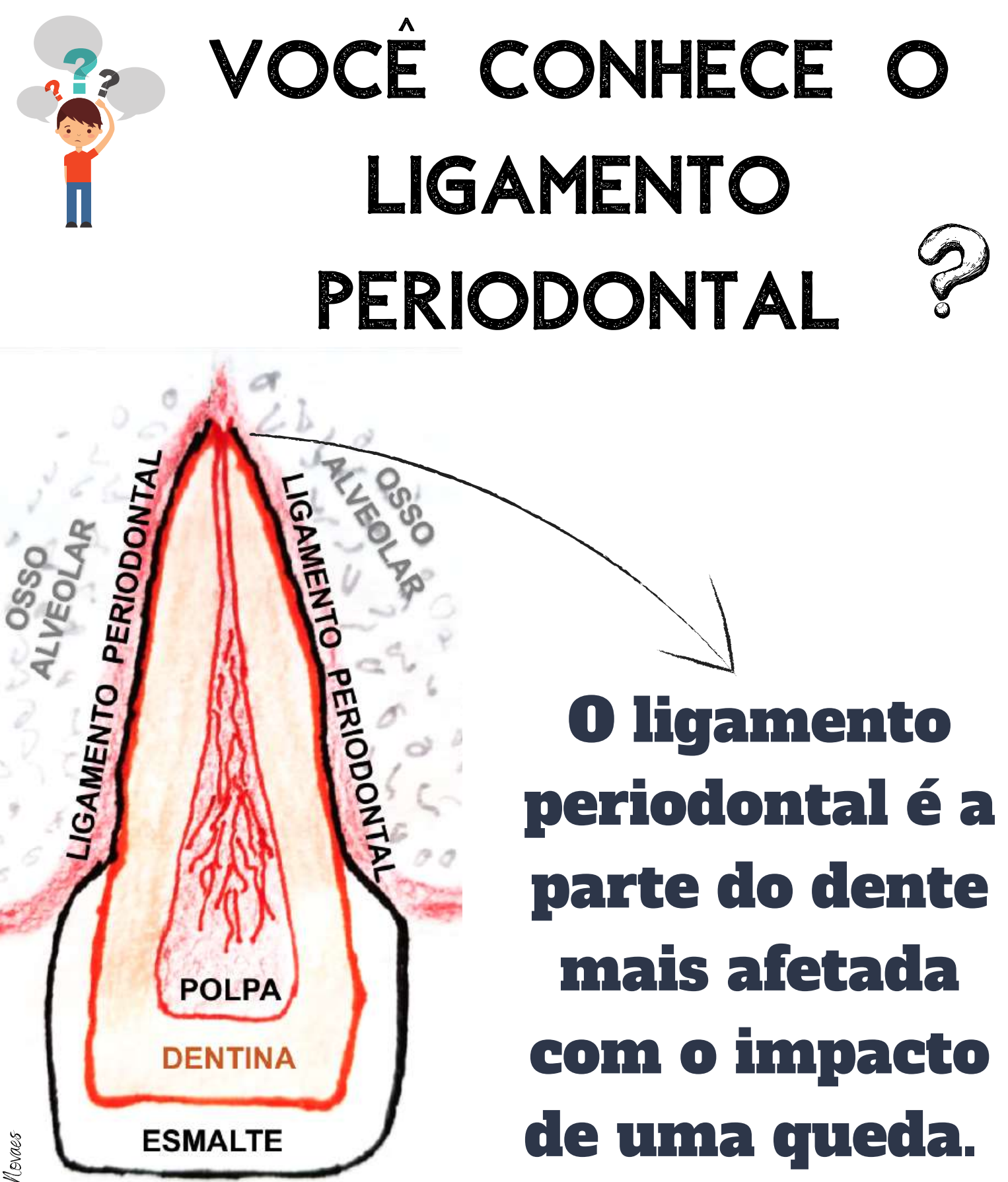




\section{QUANDO O LIGAMENTO PERIOdONTAL É ATINGIDO, PODE OGORRER:}
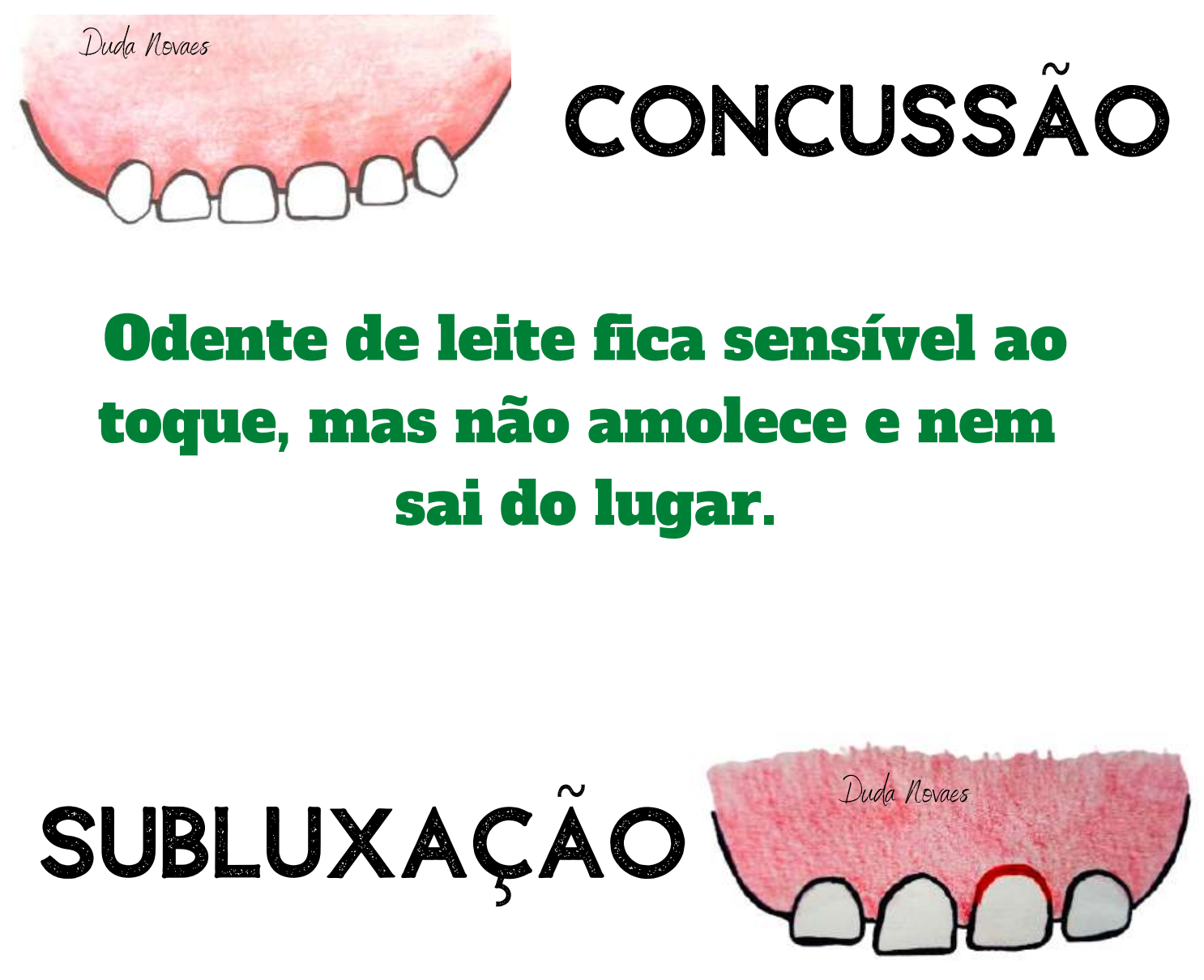

O impacto é um pouco mais forte, podendo haver sangramento gengival e uma pequena mobilidade do dente. 

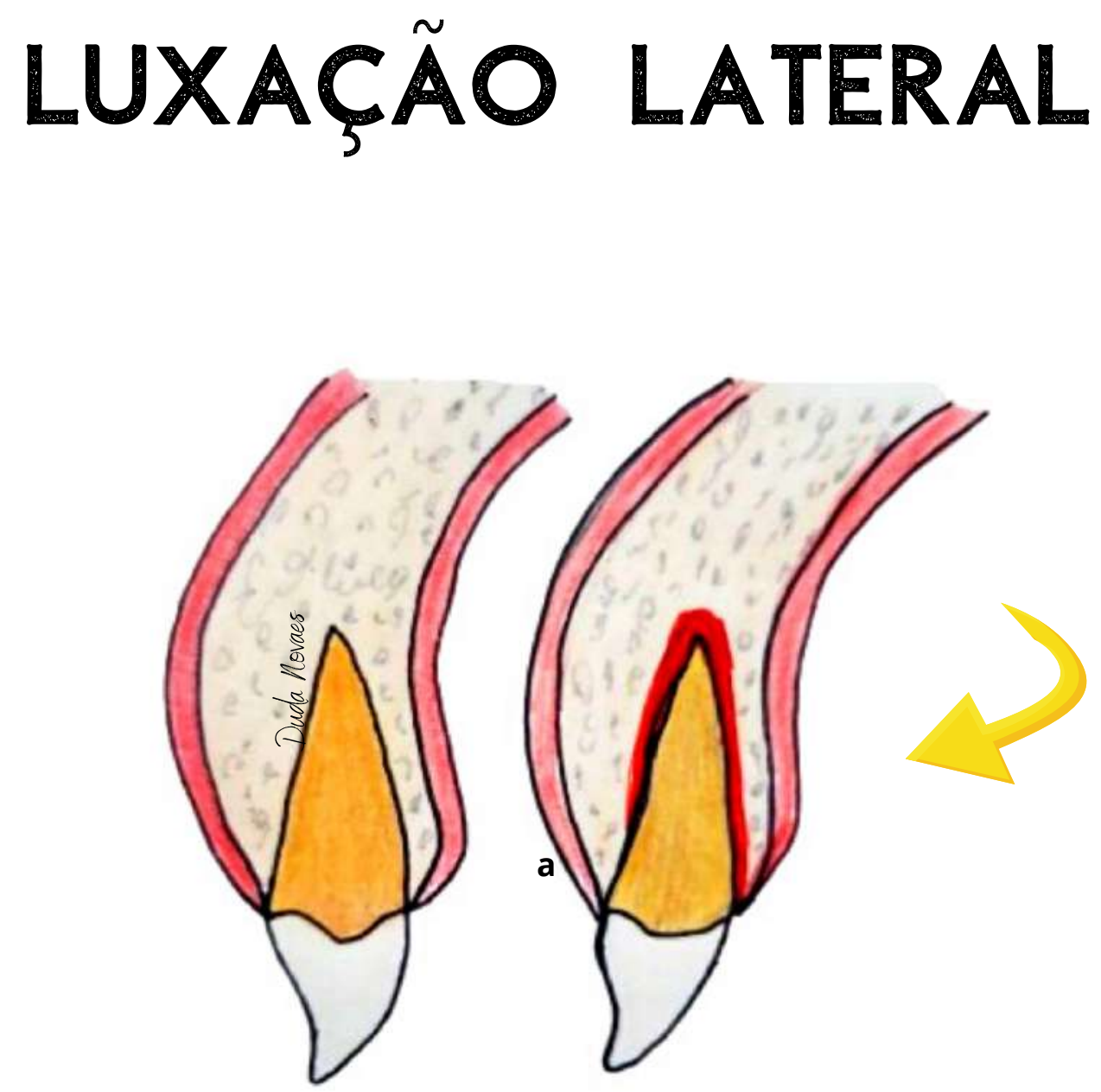

O dente de leite pode ser deslocado e mudar de posição pelo traumatismo. Fle pode ficar "desalinhado" de seus dentes vizinhos, ficando mais para frente, para trás ou para os lados. 


\section{INTRUSÃO}

\section{Fm alguns casos, apesar de não haver fratura, o dente pode ser deslocado para dentro da gengiva, parcial ou totalmente.}
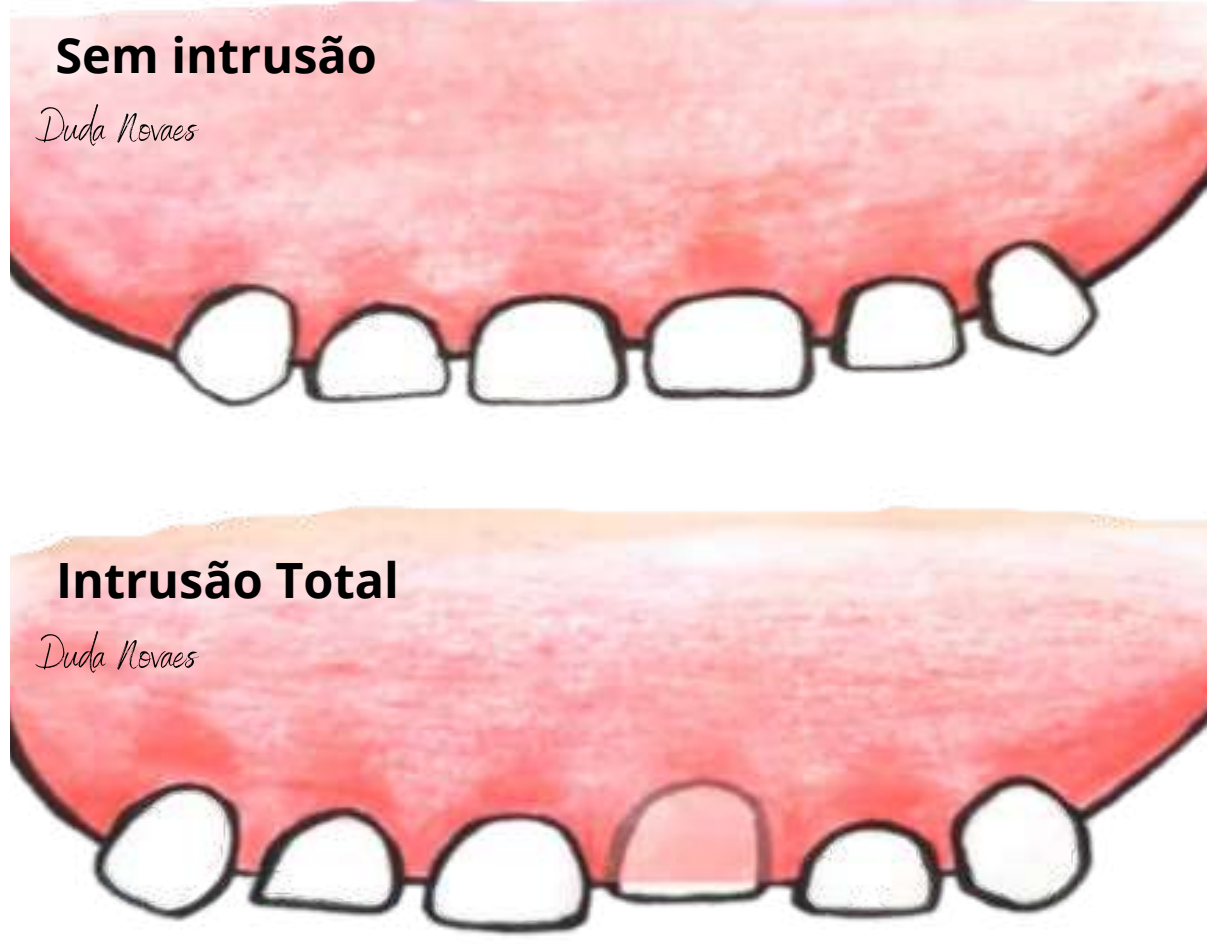


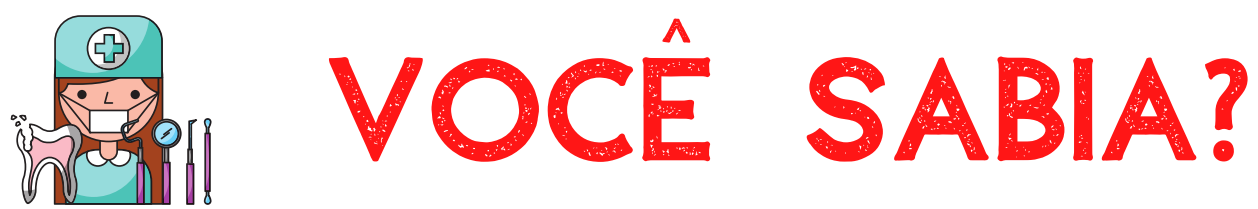

\section{O dente de leite que sofreu intrusão pode "nascer de novo" !}

\section{Em muitos casos, ele volta ao seu lugar sem precisar intervir.}

\section{Procure um dentista que ele vai te explicar melhor como isso acontece.}

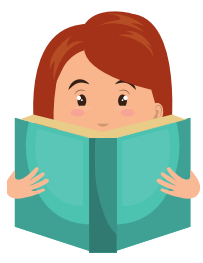




\section{EXTRUSÃO}

\section{O dente é deslocado para fora da}

gengiva e apresenta grande mobilidade

\section{(o dente fica "mole").}

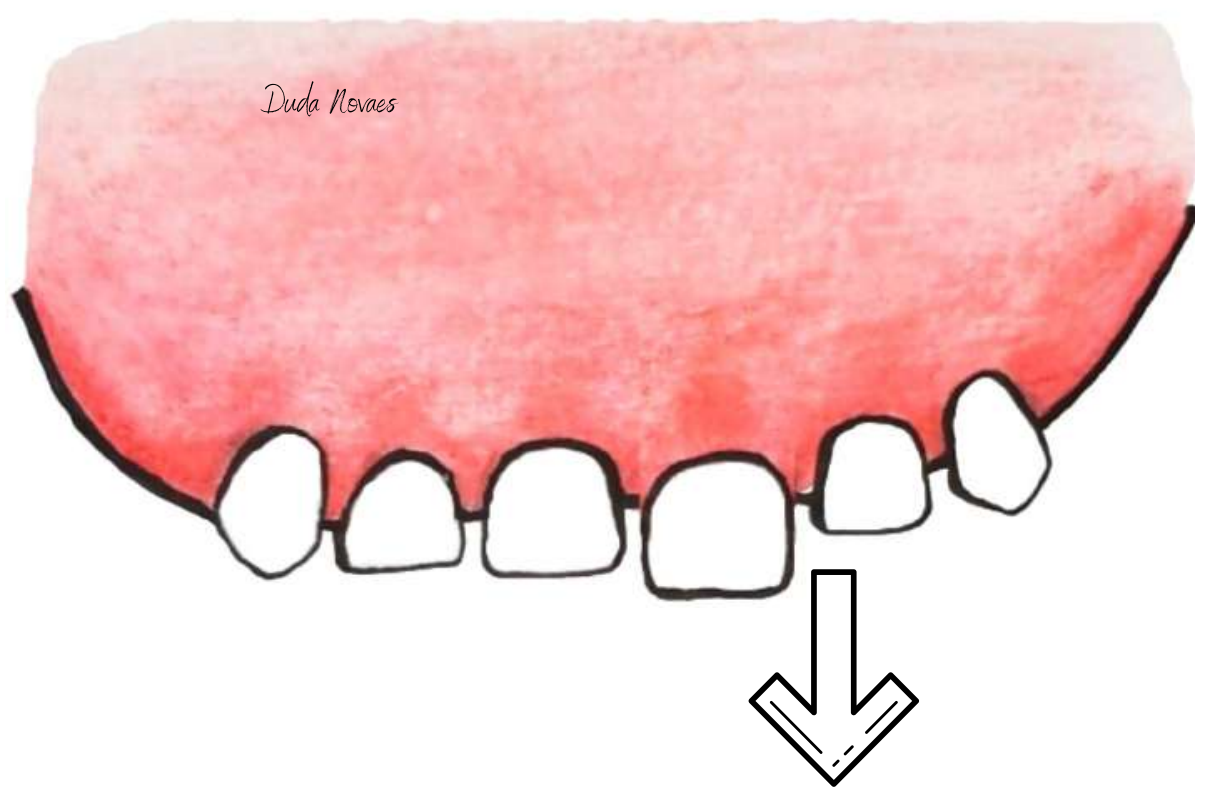

Day $P$ et al. International Association of Dental Traumatology_guidelines for the management of traumatic dental injuries: 3. Injuries in the primary dentition. Dent Traumatol. 2020. https://doi.org/10.1111/edt.12576 


\section{AVULSÃO DENTÁRIA}

É quando o dente sai por completo da gengiva/boca.

ATENÇÃO: Após um episódio de avulsão, os dentes decíduos NÃO devem ser reposicionados na boca.

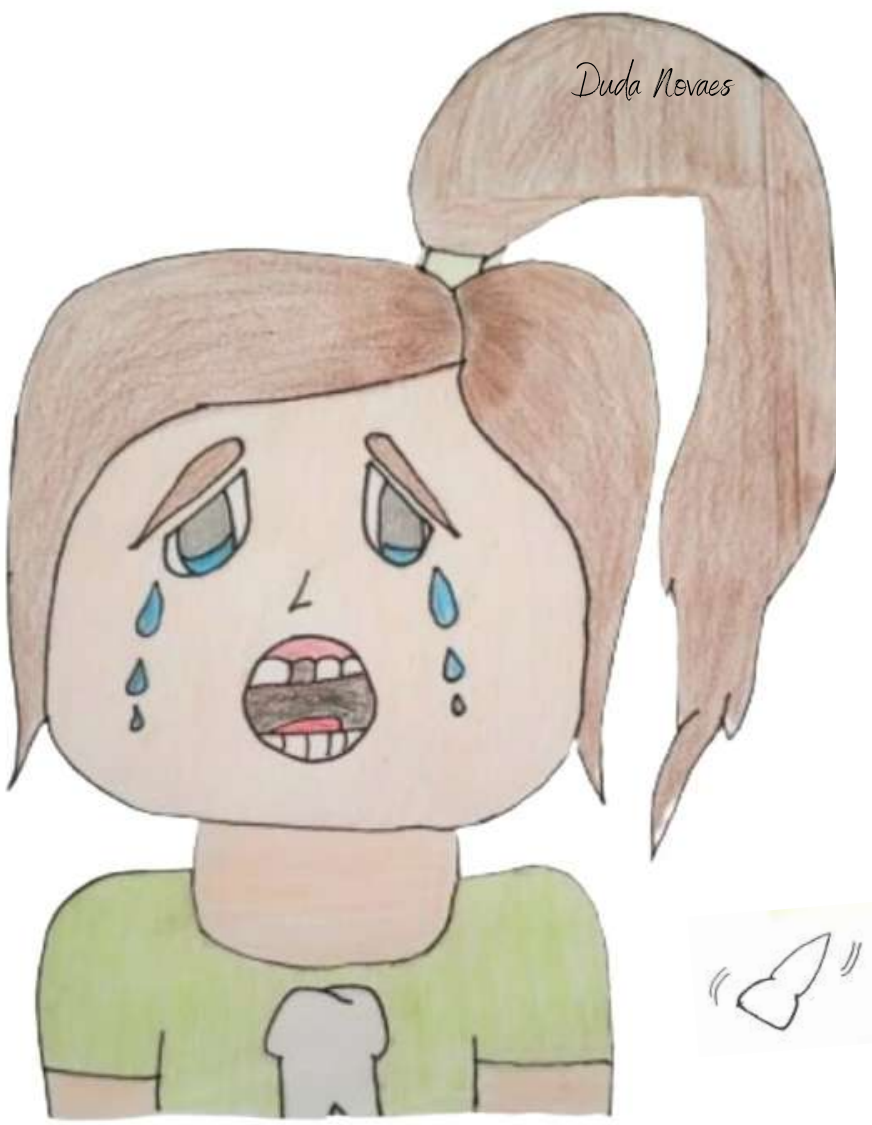

O reposicionamento (reimplante) não é recomendado em dentes de leite. 




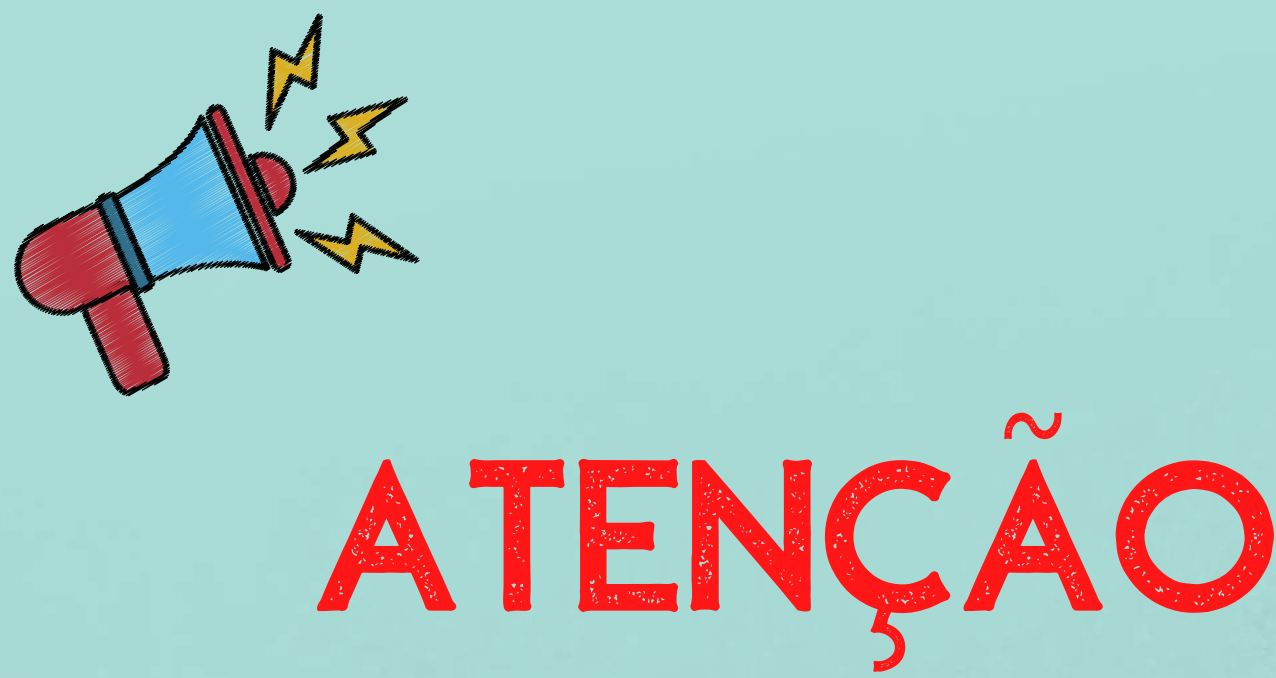

\section{Os cuidados e socorro}

oferecidos imediatamente

após um episódio de traumatismo são

fundamentais para bons

resultados no tratamento e

para um menor número de complicações! 

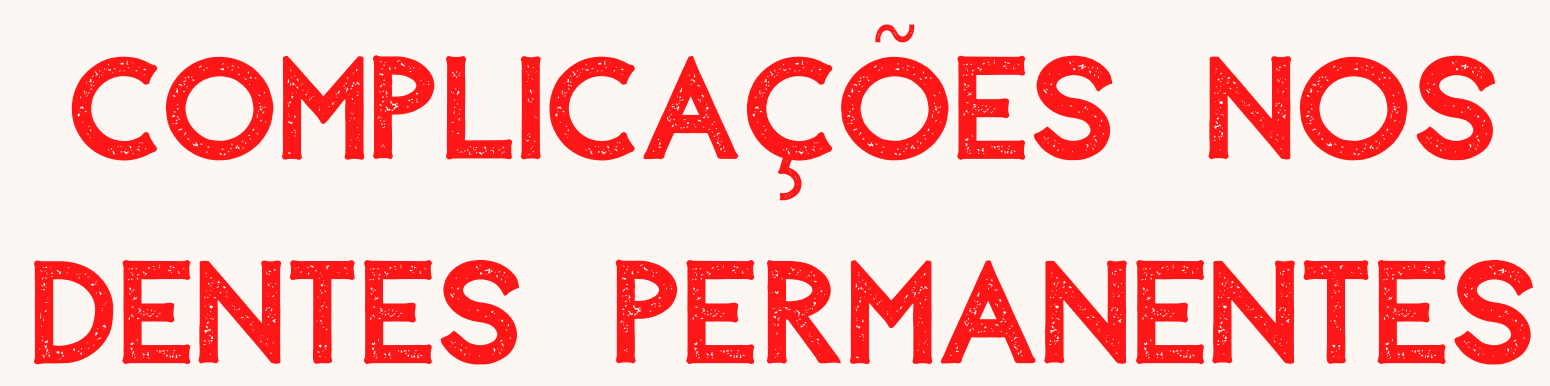

O traumatismo no dente de leite também pode trazer complicações para os dentes permanentes em desenvolvimento, tais como:

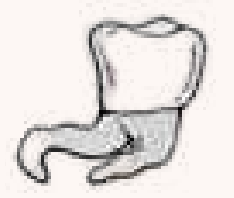

\section{Dilaceração (alteração na forma) da coroa ou raiz,}

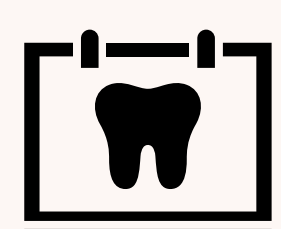

- 000

A formação de cistos (lesões envolvendo o osso) pode impedir a erupção do dente permanente (ele não nasce, não aparece na boca). 

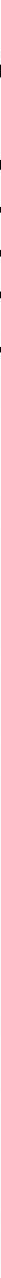

Raylla Virgínia da Silva Ramalho Souza (0) rayvramalho

Aluna do Curso de Graduação em Odontologia da Universidade Cruzeiro do Sul http://lattes.cnpq.br/4349205929636468

Fernanda Pires do N. Arena (O) nanda_arena

Cirurgiã-Dentista e Aluna do Curso de Mestrado do Programa de Pós-graduação em Odontologia da Universidade Cruzeiro do Sul http://lattes.cnpq.br/6928557486786649
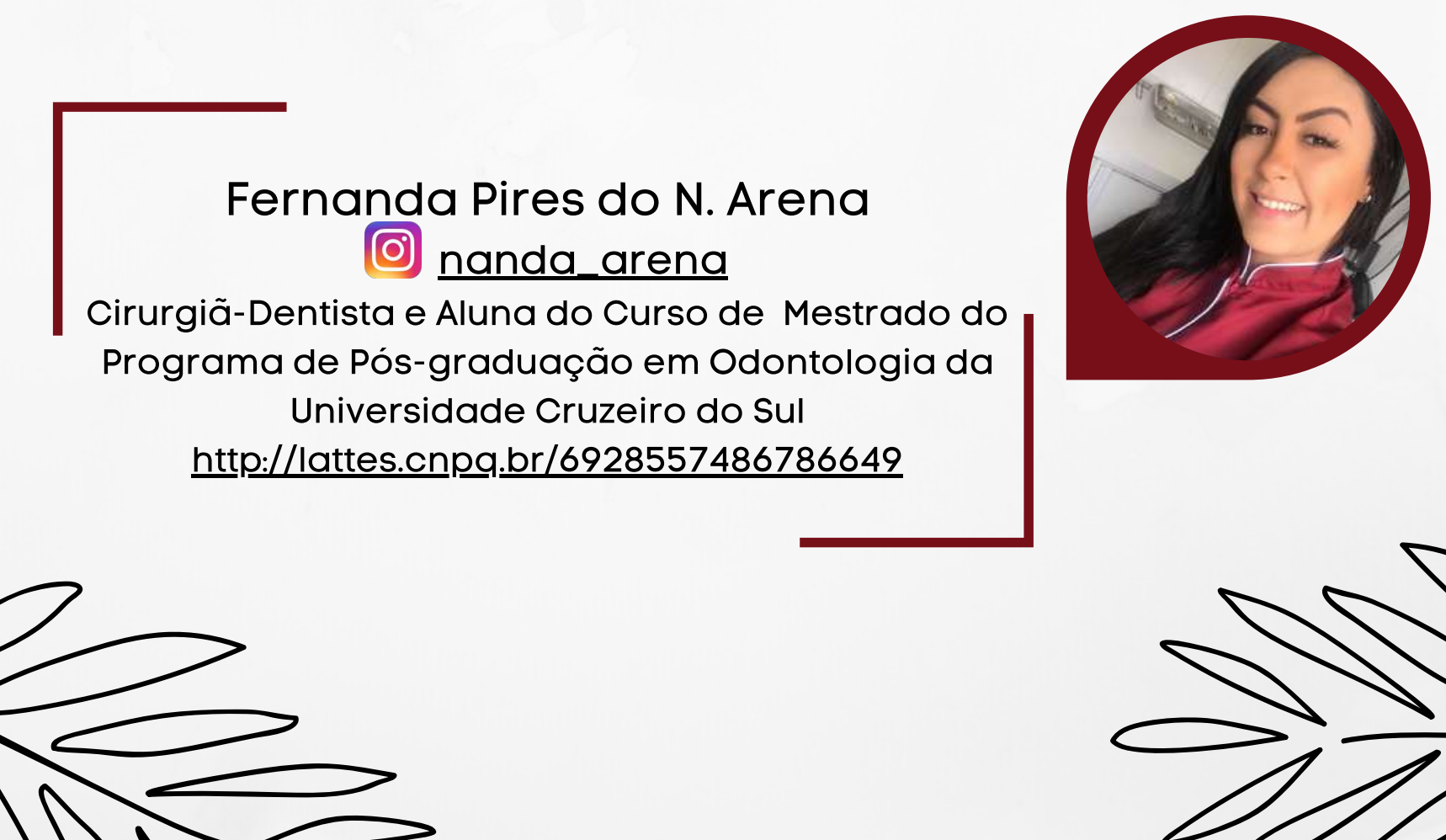


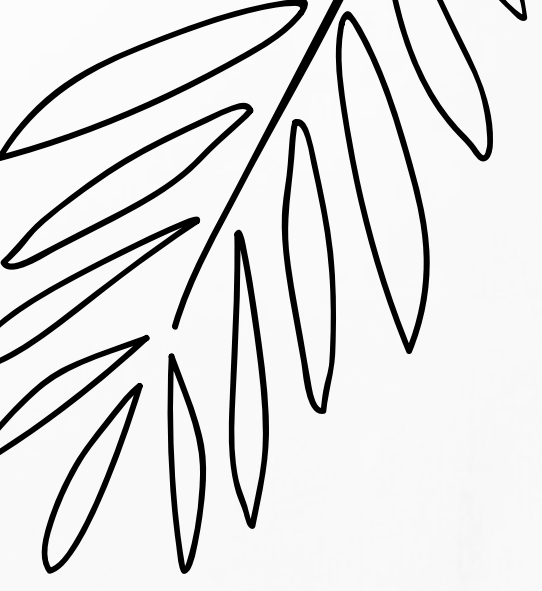

\section{autores}
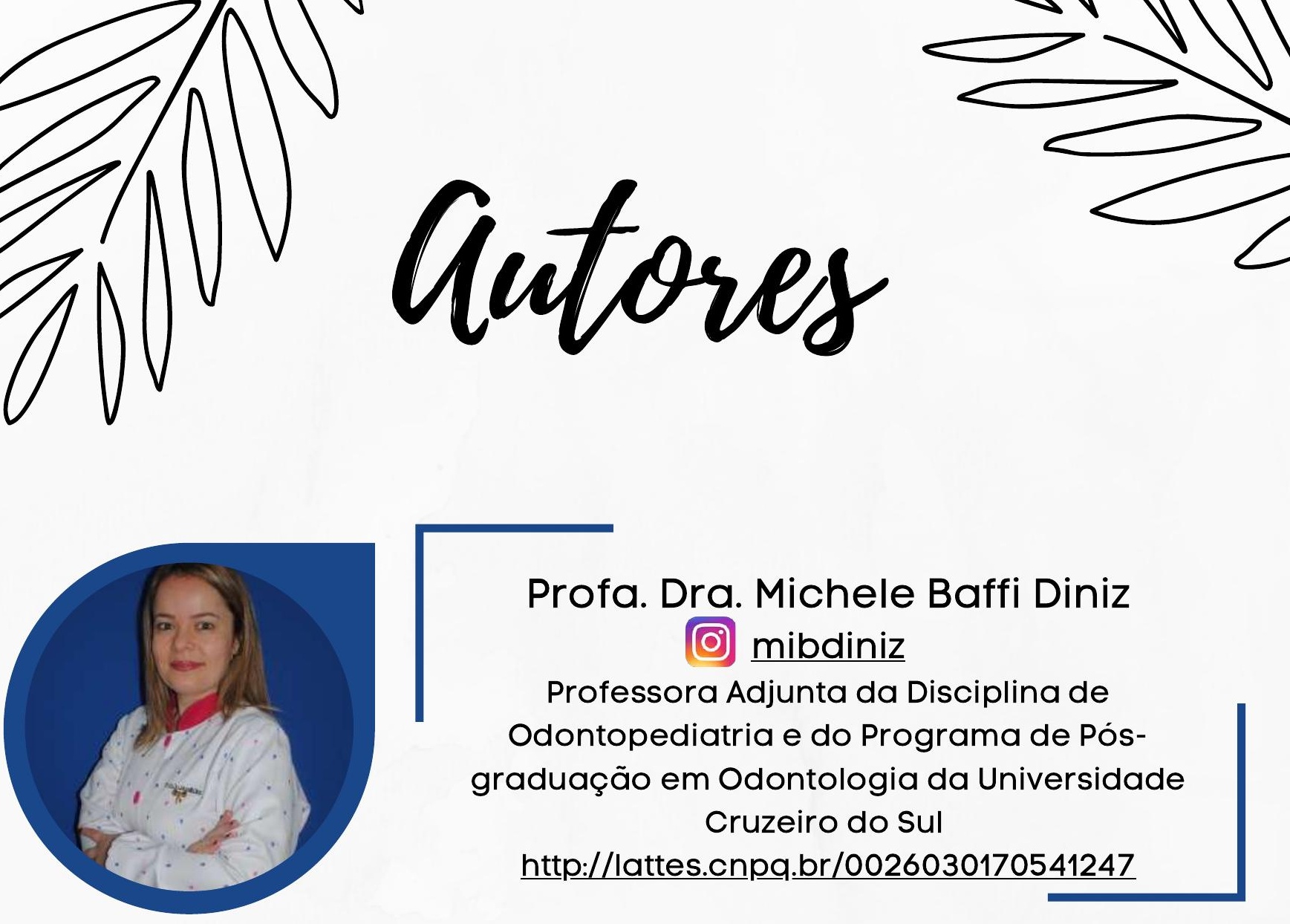

\section{Profa. Dra. Michele Baffi Diniz}

(0) mibdiniz

Professora Adjunta da Disciplina de

Odontopediatria e do Programa de Pós-

graduação em Odontologia da Universidade

Cruzeiro do sul

http://lattes.cnpq.br/0026030170541247

\section{Profa. Dra. Tatiane F. de Novaes}

(0) tatianenovaes

Professora Adjunta do Programa de Pós-graduação em Odontologia da Universidade Cruzeiro do Sul

e Colaboradora do grupo de Pesquisa

Cardec Trials FOUSP

http://lattes.cnpq.br/2749091642359010
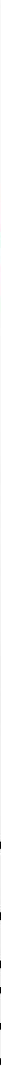


\section{Ilustracões}
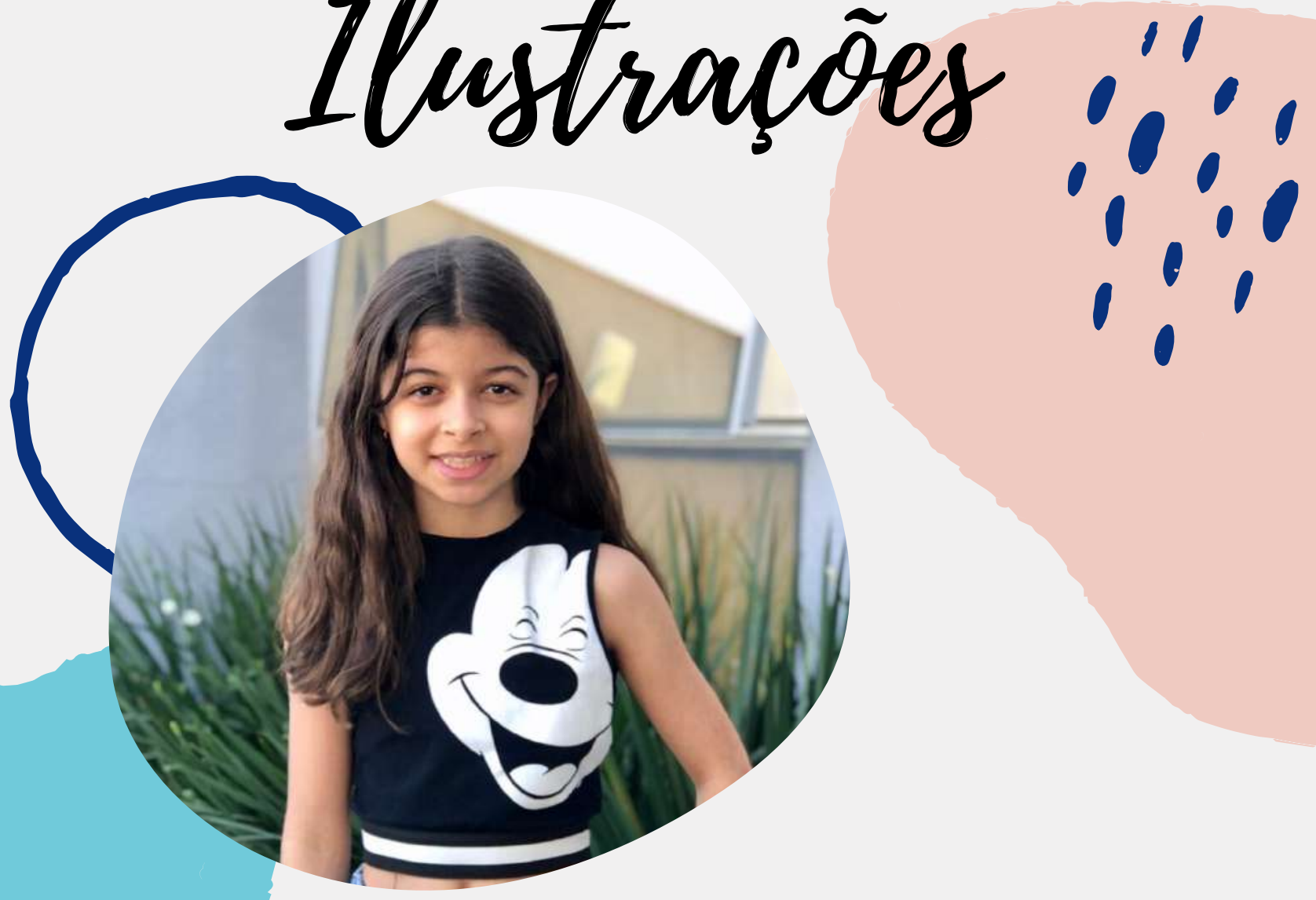

Maria Eduarda Novaes é uma menina de 10 anos que sempre adorou desenhar. Ela é filha da Profa Tatiane, que é uma das autoras desse e-book Inspirada no trabalho da mamãe, a Duda encarou o desafio e foi nossa ilustradora. 


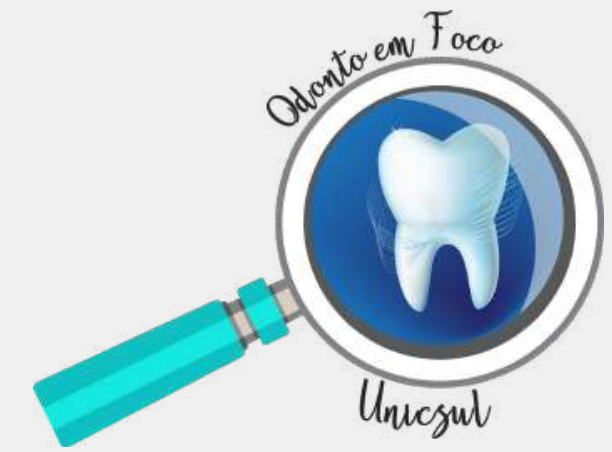




\section{Fundação Faculdade}

de Odontologia conveniado ò Fousp
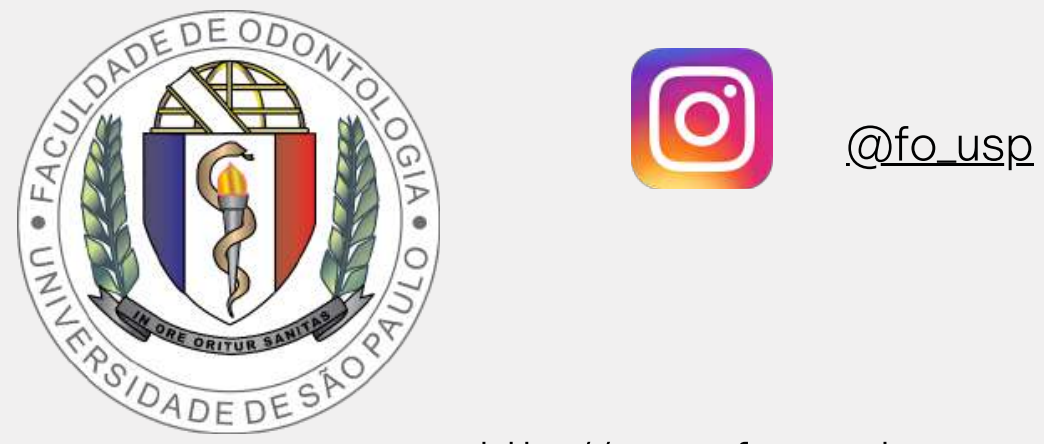

http://www.fo.usp.br
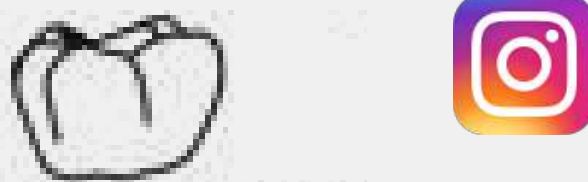

@cardec_trials

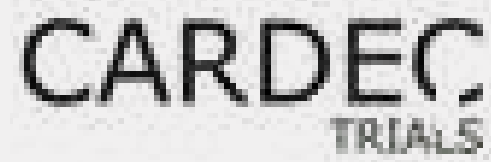

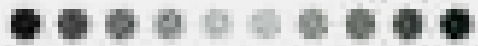

https://sites.usp.br/cardec/ 